\title{
Interceptor drainage modelling to manage high groundwater table on the Abyek Plain, Iran
}

\begin{abstract}
High groundwater tables and soil salinity are a serious threat to agricultural areas, especially on the Abyek Plain, Iran. An interceptor drainage system was installed to lower the groundwater head and control soil salinity. Simulation is an appropriate approach to investigate possible groundwater behaviour in future conditions and to explore suitable designs for implementation. Ninety-nine observation wells were installed around the interceptor drainage system in the Abyek Plain to monitor groundwater movement and salinity changes. Groundwater table fluctuation was measured monthly for 3 years from December 2010 until January 2014. A MODFLOW model was calibrated for the study area using the data measured through the observation wells. Assessment of the measured values indicated that the groundwater head was lowered within the 3 years due to the installation of the system. A calibrated model was applied to predict the future conditions of groundwater levels and suggest proper designs. Groundwater level drawdowns were predicted at approximately 1.3 and $1.5 \mathrm{~m}$ for August 2018 and August 2025, respectively. The results also revealed that with the installation of additional parallel interceptor drainage at a distance of $1000 \mathrm{~m}$ from the existing drainage, the groundwater table could be lowered in a large area of the plain.
\end{abstract}

Keyword: Interceptor drainage; MODFLOW; Groundwater table; Wells; Abyek Plain 